\title{
Germinação de Ternstroemia brasiliensis Cambess. (Pentaphylacaceae) de Floresta de Restinga
}

\author{
Luciana Andréa Pires ${ }^{1}$, Victor José Mendes Cardoso ${ }^{2,5}$, Carlos Alfredo Joly ${ }^{3}$ e Ricardo Ribeiro Rodrigues ${ }^{4}$
}

Recebido em 23/01/2008. Aceito em 3/04/2008

\begin{abstract}
RESUMO - (Germinação de Ternstroemia brasiliensis Cambess. (Pentaphylacaceae) de Floresta de Restinga). A partir de ensaios de germinação no campo e no laboratório, este trabalho visa contribuir para o conhecimento da ecologia da regeneração de Ternstroemia brasiliensis Cambess. em Floresta de Restinga. As sementes são dispersas com teores de água relativamente altos e apresentam baixa tolerância ao armazenamento, podendo ser consideradas recalcitrantes. A germinabilidade é elevada, indiferente à luz e não é afetada pela presença do arilo. A ausência de dormência e a pequena resposta ao vermelho extremo devem permitir pronta germinação no sub-bosque, não constituindo banco de sementes no solo da Restinga. As temperaturas de $25{ }^{\circ} \mathrm{C}$ e $30{ }^{\circ} \mathrm{C}$ podem ser consideradas ótimas para a germinação de T. brasiliensis. A luz pode afetar parâmetros da resposta das sementes à temperatura. A aplicação do modelo de graus-dia parece ser um instrumento válido para se estudar a dependência da temperatura da germinação dessa espécie. As características germinativas de $T$. brasiliensis são semelhantes às de espécies não-pioneiras e ajudam a explicar a distribuição da espécie. Luz e temperatura não devem ser limitantes para sua germinação no ambiente natural da Restinga, a qual pode ser influenciada principalmente pelo nível de água no solo.
\end{abstract}

Palavras-chave: Ecofisiologia, graus-dia, luz, sementes, temperatura

ABSTRACT - (Germination of Ternstroemia brasiliensis Cambess. (Pentaphylacaceae) from a Restinga Forest). The main purpose of this work was to study the germination of Ternstroemia brasiliensis seeds both in laboratory and field conditions in order to contribute to understanding the regeneration ecology of the species. The seeds were dispersed with relatively high moisture content and exhibit a recalcitrant storage behaviour because of their sensitivity to dehydration and to dry storage. The germinability is relatively high and is not affected either by light or aril presence. The absence of the dormancy and the low sensitivity to far red light can enable to seeds to promptly germinate under Restinga forest canopy, not forming a soil seed bank. The constant temperatures of $25^{\circ} \mathrm{C}$ and $30{ }^{\circ} \mathrm{C}$ were considered optimum for germination of T. brasiliensis seeds. Temperature germination parameters can be affected by light conditions. The thermal-time model can be a suitable tool for investigating the temperature dependence on the seed germination of T. brasiliensis. The germination characteristics de T. brasiliensis are typical of non pioneer species, and help to explain the distribution of the species. Germination of T. brasiliensis seeds in Restinga environment may be not limited by light and temperature; otherwise the soil moisture content can affect the seed germination.

Key words: ecophysiology, light, seeds, temperature, thermal-time

\section{Introdução}

Em florestas tropicais de terras baixas a regeneração da maioria das árvores dá-se por intermédio de sementes. Dessa forma, o conhecimento do efeito de diferentes fatores ambientais sobre a germinação é essencial para a compreensão da distribuição das espécies e dos processos operantes na comunidade como, por exemplo, o estabelecimento de plantas, a sucessão e a regeneração natural (Raich \& Khoon 1990; Vázquez-Yanes \& Orozco-Segovia 1990). Muitos estudos têm revelado que a composição distinta de espécies nas unidades vegetacionais que formam as florestas tropicais
(Whitmore 1978) está relacionada tanto às condições biofísicas que variam conforme os diferentes microambientes da floresta, tais como clareiras e/ou áreas sujeitas a alagamento (Denslow 1980; Joly 1991), como também aos requerimentos e adaptações específicas à germinação e estabelecimento das plantas.

A germinação está intimamente associada ao ambiente ao qual a planta está adaptada, sendo as sementes sensíveis a numerosos sinais de seu ambiente, como luz, temperatura, umidade e oxigênio (Mayer \& Poljakoff-Mayber 1989). O estudo da dependência da temperatura na germinação de uma espécie pode fornecer dados importantes para o entendimento da sua

\footnotetext{
Fundação Oswaldo Cruz, PVDIGT, 21045-900 Rio de Janeiro, RJ, Brasil

2 Universidade Estadual Paulista, Departamento de Botânica, C. Postal 199, 13506-900 Rio Claro, SP, Brasil

3 Universidade Estadual de Campinas, Departamento de Botânica, C. Postal 6109, 13083-970 Campinas, SP, Brasil

4 Escola Superior de Agricultura Luiz de Queiroz, Departamento de Ciências Biológicas, C. Postal 9, 13418-900 Piracicaba, SP, Brasil

5 Autor para correspondência: victorjc@ rc.unesp.br
} 
distribuição geográfica (Labouriau 1983). Segundo Swaine \& Whitmore (1988) as características da semente e da germinação das espécies tropicais são determinantes para a classificação dessas em categorias ecológicas de sucessão, assumindo como pioneiras apenas aquelas que necessitam de luz para germinar. Informações sobre o efeito do alagamento, resultando numa baixa disponibilidade de oxigênio no solo, contribuem para a compreensão da distribuição de árvores neotropicais em ambientes sujeitos a essa condição. Tais espécies exibem uma gama de comportamentos, indo desde aquelas que não germinam em condições de excesso de água no solo, até aquelas capazes de germinar em condições de hipoxia ou anoxia (Joly 1991; Lobo \& Joly 1996).

As florestas de Restinga ocorrem sobre a planície costeira arenosa e contam com um mosaico vegetacional condicionado principalmente às particularidades do substrato que, devido à oscilação do lençol freático durante o ano e às variações micro-topográficas súbitas, apresenta acentuados gradientes de umidade em áreas e períodos muito próximos (Silva \& Britez 2005; Scarano et al. 1997).

Ternstroemia brasiliensis Cambess. (pinta-noiva) é uma árvore perenifólia, 4 a 12 m de altura, ornitocórica, fruto tipo baga, deiscente, com cinco a dez sementes ariladas de vermelho intenso (Souza \& Lorenzi 2005). Ocorre geralmente em solos bem drenados, em florestas de altitude e de planícies litorâneas (Souza \& Lorenzi 2005; Oliveira Filho et al. 2004). Apresenta alto valor de importância em diversas fisionomias de Restinga do sul do Estado de São Paulo e norte do Paraná (Sugiyama 1998; Silva \& Britez 2005), sendo classificada como espécie secundária (Carrasco, comunicação pessoal) ou como pioneira antrópica em floresta secundária de planície (Salimon \& Negrelle 2001).

Apesar do incremento das pesquisas sobre ecofisiologia de espécies de Restinga nos últimos anos (Scarano et al. 1997; Pinheiro \& Borghetti 2003), muitos trabalhos ainda são necessários - particularmente com relação às fases iniciais do desenvolvimento da planta - no sentido de auxiliar o entendimento da dinâmica florestal e contribuir para ações de conservação e recuperação deste bioma, altamente sujeito à degradação.

Este trabalho é integrante do Projeto temático "Diversidade, Dinâmica e Conservação em Florestas do Estado de São Paulo: 40 ha de Parcelas Permanentes" (BIOTA- FAPESP), que possui uma parcela permanente de 10,24 ha em trecho de Floresta de Restinga na Ilha do Cardoso - São Paulo, onde Terstroemia brasiliensis contribui com 3,5\% das árvores (Oliveira et al., dados não publicados). Tem como objetivo colher informações sobre o comportamento germinativo desta espécie em resposta a diferentes condições de luz e temperatura, alagamento do substrato e presença de arilo, bem como discutir seu papel como fatores limitantes da germinação e distribuição dessa espécie no ambiente natural.

\section{Material e métodos}

As sementes de Terstroemia brasiliensis Cambess. foram coletadas no Parque Estadual da Ilha do Cardoso,

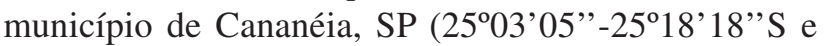
$47^{\circ} 53^{\prime} 48^{\prime \prime}-48^{\circ} 05^{\prime} 42^{\prime \prime} \mathrm{W}$ ), tendo pelo menos seis matrizes como fonte das sementes. Após a coleta os frutos foram transportados para laboratório, sendo o arilo removido manualmente sob água corrente, com auxílio de peneira. As sementes foram em seguida utilizadas nos experimentos, sendo algumas acondicionadas em saco plástico preto e armazenadas em sala climatizada a $25^{\circ} \mathrm{C}$ para averiguação da sua viabilidade após 30 e 60 dias. Os ensaios de laboratório foram realizados no Departamento de Botânica do Instituto de Biociências da UNESP, Campus Rio Claro, SP.

As sementes foram caracterizadas quanto ao tamanho, massa fresca (sem o arilo), conteúdo de água e embebição. O tamanho das sementes (medidas dos eixos maior e menor) e a massa fresca foram estimados a partir de uma amostra de 50 sementes. A determinação do conteúdo de água (base massa fresca) foi feita de acordo com Silva (1988). Para a curva de embebição foram utilizadas cinco repetições de dez sementes cada, as quais foram imersas em béquer com água destilada à temperatura de $25^{\circ} \mathrm{C}$. Após diferentes intervalos de tempo, as amostras foram retiradas da água e pesadas em balança semi-analítica.

Os testes de germinação em laboratório foram realizados em caixas plásticas (gerbox) transparentes para os tratamentos de luz, ou pretas para os tratamentos de escuro, tendo como substrato vermiculita saturada com água destilada. Para os ensaios simulando alagamento, adicionou-se ao substrato uma quantidade de água suficiente para cobrir toda a semente. Cada tratamento constou de cinco repetições, com 20 sementes cada. Luz branca foi obtida por intermédio de lâmpadas fluorescentes brancas, proporcionando irradiância (tomada com auxílio de radiômetro Li-Cor LI 1000) de aproximadamente $27 \mu \mathrm{mol} . \mathrm{s}^{-1} \cdot \mathrm{m}^{-2}$ (PAR) ao nível das caixas; vermelho extremo (VE) foi obtido com filtro formado por uma camada de acrílico vermelho e uma de acrílico azul, sob uma lâmpada incandescente de 40W. Esses ensaios foram feitos em sala climatizada, à temperatura de $25^{\circ} \mathrm{C}\left( \pm 2^{\circ} \mathrm{C}\right)$. Os ensaios de temperatura constante foram feitos em câmaras de germinação, sob luz branca (irradiância média de $29,3 \mu \mathrm{mol} \cdot \mathrm{m}^{-2} \cdot \mathrm{s}^{-1}$ ) e escuro, às temperaturas de $15,20,25,30$ e $35^{\circ} \mathrm{C}$ 
$\left( \pm 0,5^{\circ} \mathrm{C}\right)$. Para os tratamentos de escuro e VE, as contagens de germinação foram realizadas sob luz verde de baixa intensidade (Amaral-Baroli \& Takaki 2001). A montagem dos experimentos seguiu um delineamento inteiramente ao acaso.

A germinação (protrusão radicular) foi avaliada por intermédio dos parâmetros germinabilidade (porcentagem final de germinação); velocidade média (Labouriau \& Agudo 1987); velocidade $\left(\mathrm{V}_{\mathrm{g}}\right)$ representada pela recíproca do tempo necessário para a germinação de uma determinada fração percentual (Garcia-Huidobro et al. 1982); e sincronização da germinação (U) expressa em bits, por intermédio da expressão $U=\Sigma\left(\mathrm{f}_{\mathrm{i}} \cdot \log _{2} \mathrm{f}_{\mathrm{i}}\right)$, onde $\mathrm{f}_{\mathrm{i}}$ é o número de sementes germinadas no tempo $i$ dividido pelo número total de sementes germinadas (Labouriau \& Agudo 1987). As médias das germinabilidades e sincronização foram submetidas a análise de variância (ANOVA) e comparadas pelo teste de Tukey ( $\alpha=0,05)$, enquanto que as velocidades médias, cujas variâncias apresentaram heterogeneidade (teste de Bartlett), foram comparadas pelo teste não paramétrico de Mann-Whitney (Sokal \& Rohlf 1969).

Para a análise da dependência da temperatura das curvas de germinação (temperaturas sub-ótimas) foi aplicado o modelo de graus-dia, $\left[\theta_{\mathrm{g}}=\left(\mathrm{T}-\mathrm{T}_{\mathrm{b}}\right) . \mathrm{t}_{\mathrm{g}}\right]$, onde: $\theta_{\mathrm{g}}$ é a quantidade de graus-dia necessária para a germinação da fração $g$; T é a temperatura experimental; $\mathrm{T}_{\mathrm{b}}$ a temperatura base ou mínima de germinação; e $\mathrm{t}_{\mathrm{g}} \mathrm{o}$ tempo necessário para a germinação da fração percentual $g$ (Garcia-Huidobro et al. 1982). Os parâmetros $\mathrm{T}_{\mathrm{b}}$ e $\theta_{\mathrm{g}}$ foram estimados de acordo com Bradford (1995) e Garcia-Huidobro et al. (1982). A relação entre a distribuição de $\theta_{\mathrm{g}}$ e as porcentagens de germinação foi feita a partir da equação $\left[\operatorname{probit}(g)=5+(1 / \sigma) .\left(\log \theta_{g}-\mu\right)\right]$, onde: $\sigma$ (desvio padrão) é a recíproca da inclinação da reta de $\log \theta_{\mathrm{g}}$ versus probit $g$; e $\mu$ o valor mediano da distribuição de $\theta_{\mathrm{g}}$ (Gummerson 1986; Bradford 1995). Esse modelo assume que $\theta_{\mathrm{g}}$ apresenta distribuição normal dentro da população de sementes.

Os ensaios de campo foram realizados no interior de uma parcela (10,24 ha) do projeto "Parcelas Permanentes" na Floresta de Restinga, no mesmo local onde foram coletadas as sementes. Os pontos de amostragem foram distribuídos em ambientes selecionados de acordo com a abertura do dossel e nível aparente de água no solo, sendo tais ambientes denominados neste trabalho: sub-bosque seco (SS); subbosque úmido (SU); clareira seca (CS); e clareira úmida (CU). Uma caracterização dos diferentes ambientes em termos de irradiância (PAR) média ao nível do solo e teores de água no solo é apresentada (Fig. 1). As irradiâncias foram tomadas por meio de radiômetro LI 1000 (LiCOR) e a umidade superficial do solo $(0-5 \mathrm{~cm})$
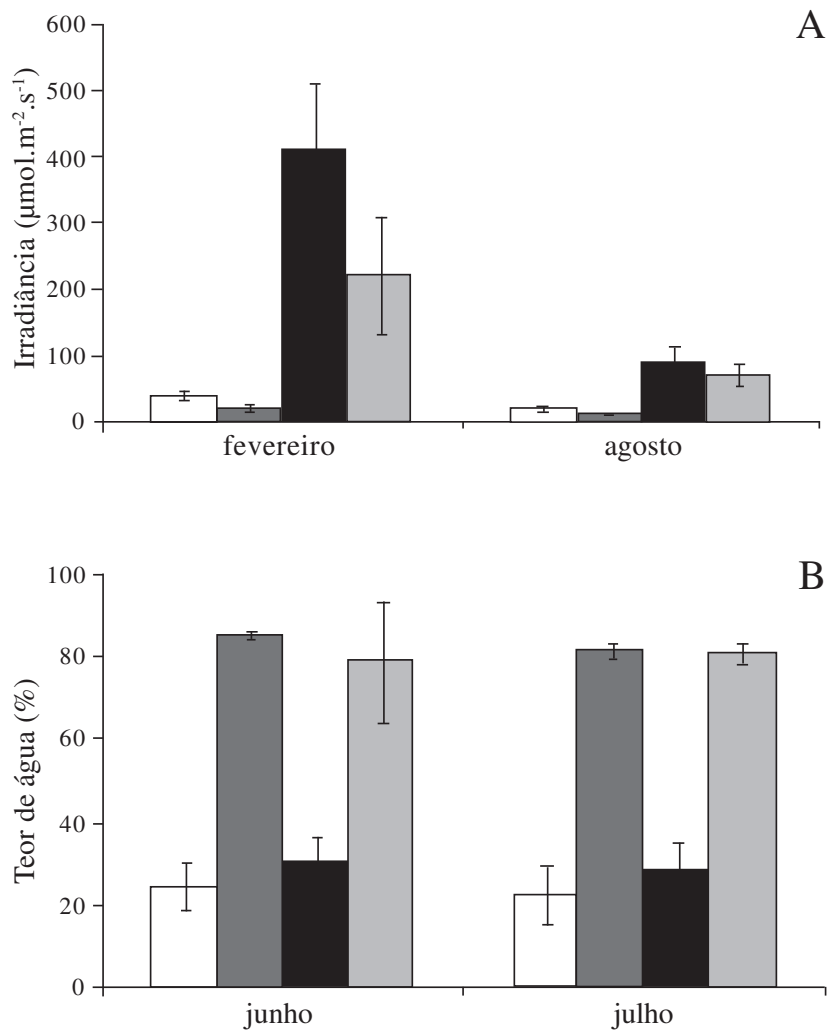

Figura 1. Radiação fotossinteticamente ativa (PAR) e porcentagem de umidade superficial do solo coletadas em duas épocas do ano, no período de montagem dos ensaios de germinação no campo, nos ambientes classificados como sub-bosque seco (SS), sub-bosque úmido (SU), clareira seca (CS) e clareira úmida (CU), em uma floresta de Restinga na Ilha do Cardoso, SP, Brasil. Barras indicam os respectivos erros da média. $(\square=\mathrm{SS} ; \boldsymbol{-} \mathrm{SU} ; \boldsymbol{\square}=\mathrm{CS} ;=\mathrm{nU})$.

obtida por método gravimétrico. Considerando-se a época da montagem dos ensaios, são apresentados apenas os valores de umidade referentes a junho e julho/2004 (Fig. 1B). As temperaturas médias anuais (mínima e máxima) nos ambientes SS, SU, CS e CU foram, respectivamente: $14,5-28,5{ }^{\circ} \mathrm{C} ; 13,8-28,7{ }^{\circ} \mathrm{C}$; 13,6-33,8 ${ }^{\circ} \mathrm{C}$; e $14,3-33,1{ }^{\circ} \mathrm{C}$.

Para os ensaios de germinação na superfície, amostras de 30 sementes foram colocadas diretamente sobre o solo, num espaço circunscrito por um anel de PVC de $12 \mathrm{~cm}$ diâm. e $5 \mathrm{~cm}$ alt. acima do solo. Esses anéis foram cobertos com tela de filó para se evitar o acesso de predadores, bem como a entrada de novas sementes. Foram feitas cinco repetições por ambiente, distantes pelo menos $20 \mathrm{~m}$ entre si, sendo o experimento acompanhado mensalmente. Com o intuito de se acompanhar a longevidade das sementes enterradas no ambiente natural, amostras de 20 sementes cada foram colocadas em envelopes de tela de náilon $(12 \times 12 \mathrm{~cm})$ preenchidos com solo do local e enterrados a $5 \mathrm{~cm}$ de profundidade. Os envelopes foram enterrados nos mesmos locais dos ensaios de germinação. Mensalmente, 
cinco envelopes eram retirados de cada ambiente, avaliando-se o número de sementes germinadas no campo e testando-se em laboratório a $25^{\circ} \mathrm{C}$ sob luz branca a germinação das sementes exumadas presentes nas amostras.

\section{Resultados}

Quanto aos parâmetros morfológicos, as sementes de Terstroemia brasiliensis apresentaram um tamanho médio de 6,4 $\mathrm{mm}$ (eixo maior) por $4 \mathrm{~mm}$ (eixo menor); massa de $26 \mathrm{mg}$; e teor de umidade de $37 \%$. Após 30 e 60 dias de armazenamento os níveis de umidade das sementes caíram, respectivamente, para $22,2 \%$ e $14,8 \%$. A taxa de hidratação da semente foi relativamente rápida, atingindo $72 \%$ (base massa de matéria fresca) após 24 horas de imersão em água e estabilizando-se em seguida.

A germinabilidade de Terstroemia brasiliensis não diferiu comparando-se entre si os tratamentos de luz branca, escuro e vermelho extremo (Fig. 2A). Nas condições experimentais aplicadas, não se observou diferença na germinabilidade sob luz branca de sementes com e sem arilo, ocorrendo forte inibição da germinabilidade em sementes cobertas com água e mantidas sob luz branca (Fig. 2A). Quanto à velocidade de germinação também não houve diferença entre os tratamentos de luz branca e escuro constantes, e de sementes com e sem arilo. Por outro lado, o vermelho extremo inibiu a velocidade de germinação em relação à luz branca e escuro, produzindo valores equivalentes aos das sementes imersas (Fig. 2B).

A germinação final foi elevada (ao redor de 90\%) na faixa térmica de 15 a $35{ }^{\circ} \mathrm{C}$, não se observando diferenças significativas entre as temperaturas sob luz branca (Fig. 3A). Em escuro ocorreu uma redução na germinabilidade a $35^{\circ} \mathrm{C}$ (Fig. 3B). Quanto à velocidade de germinação, representada pela recíproca dos tempos necessários para a germinação das frações percentuais de $5,10,20,30,40,50,60,70,80$ e $90 \%$, observa-se um aumento da velocidade com a elevação da temperatura no intervalo de $15{ }^{\circ} \mathrm{C}$ a $25{ }^{\circ} \mathrm{C}$, tanto sob luz branca (Fig. 3C) como em escuro (Fig. 3D). Acima de $25^{\circ} \mathrm{C}$ sob luz branca e acima de $30^{\circ} \mathrm{C}$ em escuro observa-se um decréscimo da velocidade em relação a todas as frações. Com base neste experimento pode-se dizer que a velocidade é máxima às temperaturas de $25^{\circ} \mathrm{C}$ e $30^{\circ} \mathrm{C}$ (Fig. 3C-D). Com relação ao índice de sincronização, que avalia o grau de dispersão da germinação ao longo do tempo, observa-se que sob luz branca a germinação tende a ser mais sincronizada ou agrupada (menores valores de $\mathrm{U}$ ) às temperaturas de $15^{\circ} \mathrm{Ce} 20^{\circ} \mathrm{C}$ (Fig. 3E), enquanto que em escuro a sincronização é maior a $35^{\circ} \mathrm{C}$ (Fig. 3F).
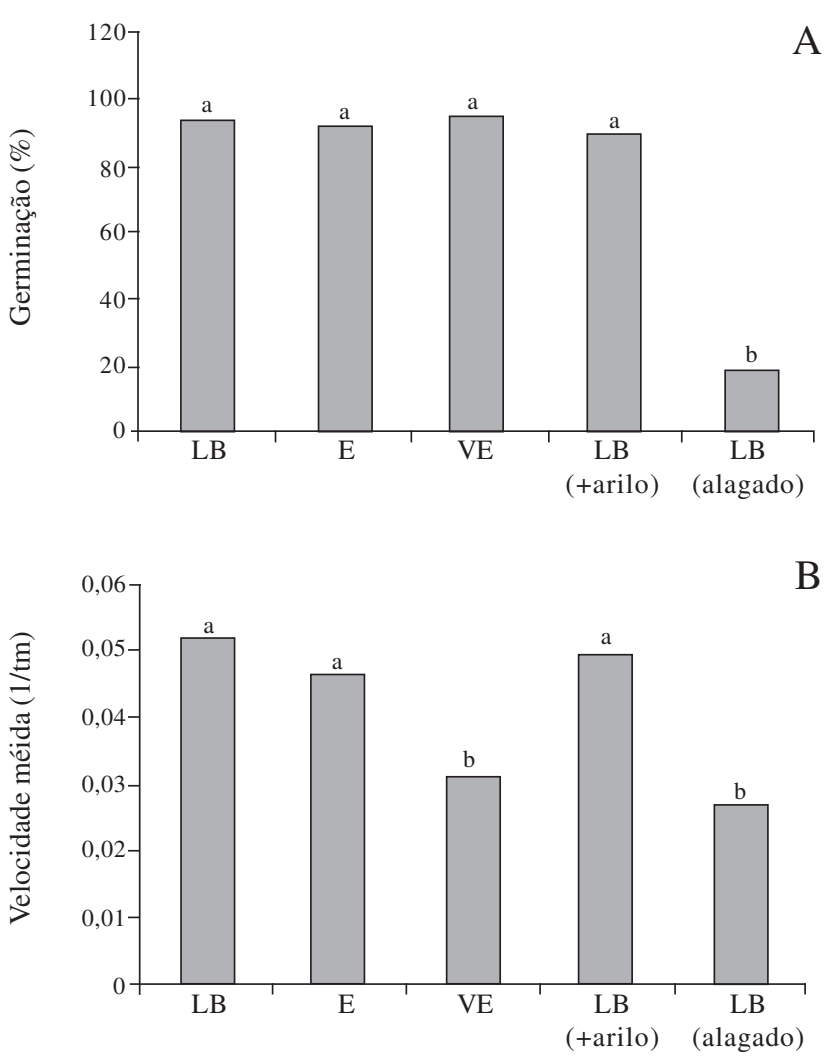

Figura 2. Germinabilidade (A) e velocidade média de germinação (B) de sementes de Terstroemia brasiliensis Cambess. sob luz branca (LB), escuro (E) e vermelho-extremo (VE); sementes com arilo mantidas sob luz (LB + arilo); e sementes imersas em água, sob luz branca (LB alagado). Todos os experimentos mantidos a $25^{\circ} \mathrm{C}$. Letras minúsculas comparam as médias $(\alpha=0,05)$; A: ANOVA seguida de teste de Tukey; B: teste de Mann-Whitney.

Tomando-se apenas as temperaturas de $15,20 \mathrm{e}$ $25^{\circ} \mathrm{C}$, onde a velocidade tende a aumentar com a elevação da temperatura, são apresentadas as distribuições das porcentagens acumuladas de germinação sob luz branca e escuro em escala de dias (símbolos, nas Fig. 4A, C). Observa-se que a redução da temperatura produz um retardamento da germinação, ou seja, a distribuição dos eventos germinativos tende a transcorrer ao longo de um tempo maior. A apresentação dessas mesmas porcentagens em escala de graus-dia (Fig. 4B-D) tende a agrupar os pontos numa única curva, particularmente para as frações percentuais abaixo de $70 \%$. O parâmetro $\mathrm{T}_{\mathrm{b}}$, estimado a partir das curvas de regressão da velocidade de germinação sobre a temperatura, apresentou os valores de $-1,5$ para sementes germinadas sob luz branca $\mathrm{e}+1$ para sementes mantidas em escuro, sugerindo que as condições de luz podem alterar os parâmetros de resposta das sementes à temperatura. A partir dos parâmetros $\mathrm{T}_{\mathrm{b}}$ e $\theta_{\mathrm{g}}$, e usando-se o modelo $\left[g=5+(1 / \sigma) .\left(\theta_{\mathrm{g}}-\mu\right)\right]$, foram calculadas as curvas teóricas de germinação representadas pelas linhas sólidas, em dias (Fig. 4A, C) e graus-dia (Fig. 4B, D), às temperaturas de 15,20 e $25^{\circ} \mathrm{C}$. 
Um teste de $\chi^{2}(\alpha=0,05)$ mostrou que a discrepância entre os pontos e as linhas tende a ser maior em sementes germinadas em escuro (Fig. 4C, D) do que sob luz branca (Fig. 4A-B), sendo que dentro dos tratamento sob luz
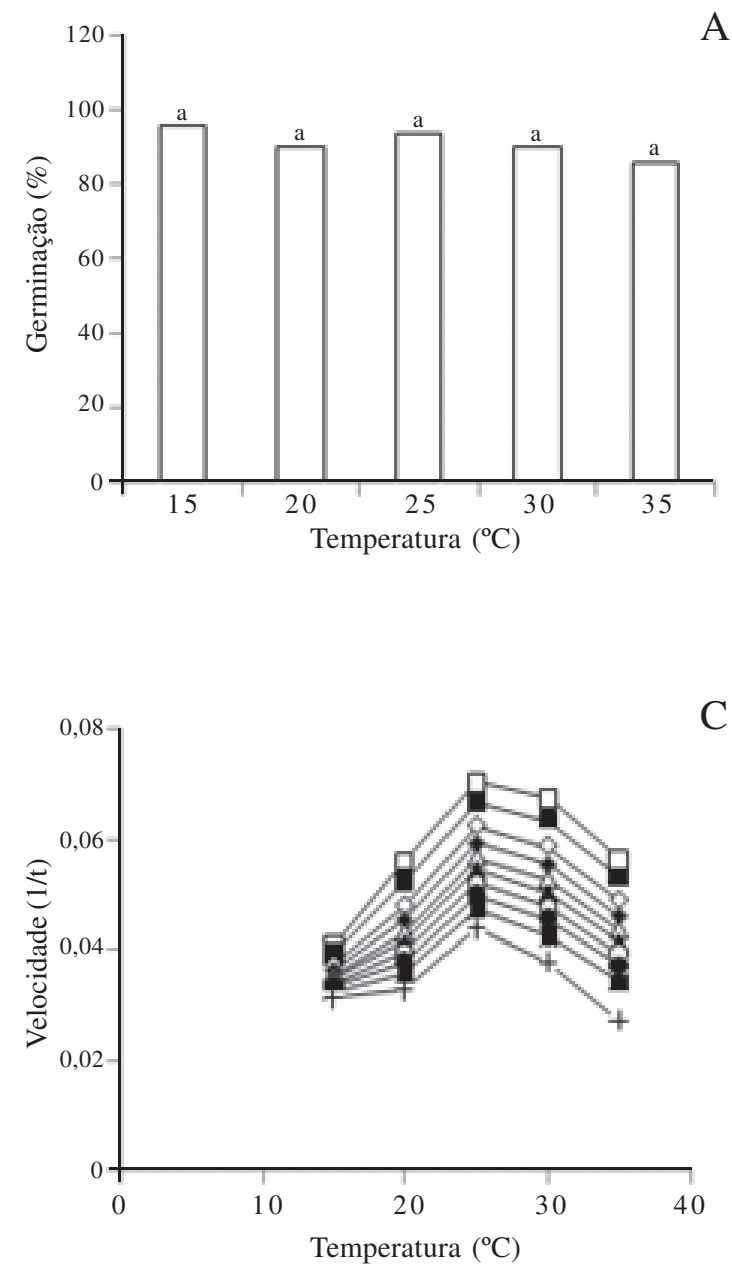

$\mathrm{E}$

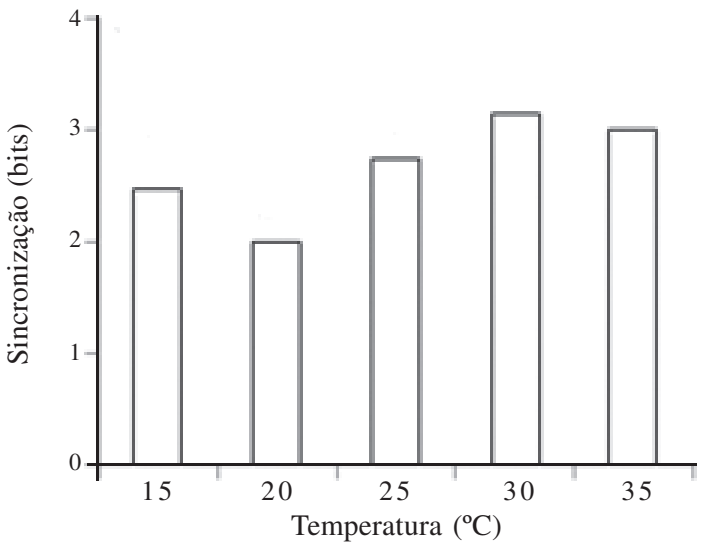

$\mathrm{C}$ tende a ocorrer maior similaridade entre os valores observados e esperados nas frações situadas na faixa de 20 a $60 \%$. A $15^{\circ} \mathrm{C}$ houve a maior divergência entre os pontos experimentais e o modelo.
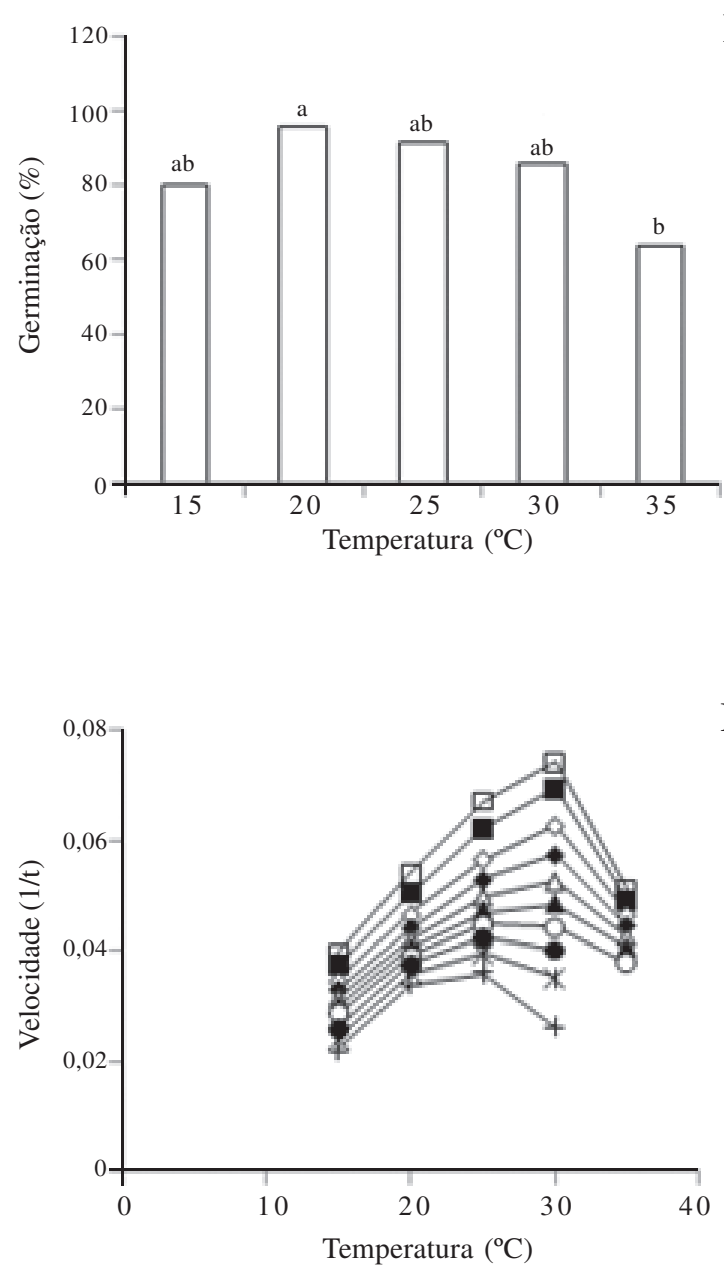

$\mathrm{F}$

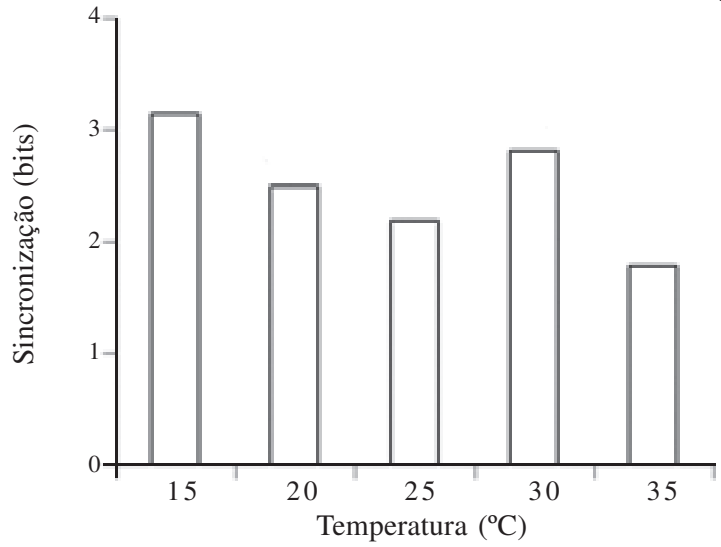

Figura 3. Germinabilidade (A e B), velocidade (C e D) e sincronização (E e F) da germinação isotérmica de sementes de Terstroemia brasiliensis Cambess. mantidas sob luz branca (A, C e E) e escuro (B, D e F). Velocidades de germinação como as recíprocas dos tempos necessários para a germinação das frações: $5(\square) ; 10(\bullet) ; 20(\diamond) ; 30(\bullet) ; 40(\Delta) ; 50(\bullet)$; $60(\circ) ; 70(\bullet)$; $80(*)$; e 90\% (+). Médias seguidas da mesma letra não diferem entre si $(\alpha=0,05$; ANOVA seguida de teste de Tukey). 
Nos ensaios de enterramento de sementes no solo da Restinga - realizados inicialmente para se avaliar a longevidade das sementes de Terstroemia brasiliensis diretamente no ambiente natural - observou-se um número relativamente grande de sementes germinadas in situ (Fig. 5A). A porcentagem de plântulas presentes nos envelopes desenterrados foi maior nos primeiros dois meses (junho e julho), decrescendo nos dois meses subseqüentes (agosto e setembro). Há que se ressaltar, por outro lado, que esse decréscimo deve-se em grande parte à morte das plântulas no interior dos envoltórios, considerando-se que em muitos casos não foram encontradas sementes inteiras nos envelopes desenterrados em agosto e setembro. Para efeito de comparação, também são apresentadas as germinabilidades de sementes armazenadas em laboratório, em teste realizado em sala climatizada. Nesse caso é possível observar que a germinabilidade foi de $100 \%$ em sementes recém-colhidas (maio), decrescendo após 30 dias de armazenamento e tornando-se praticamente nula após 60 dias (Fig. 5A). Comparando-se os diferentes ambientes quanto à presença de plântulas nos envelopes

A
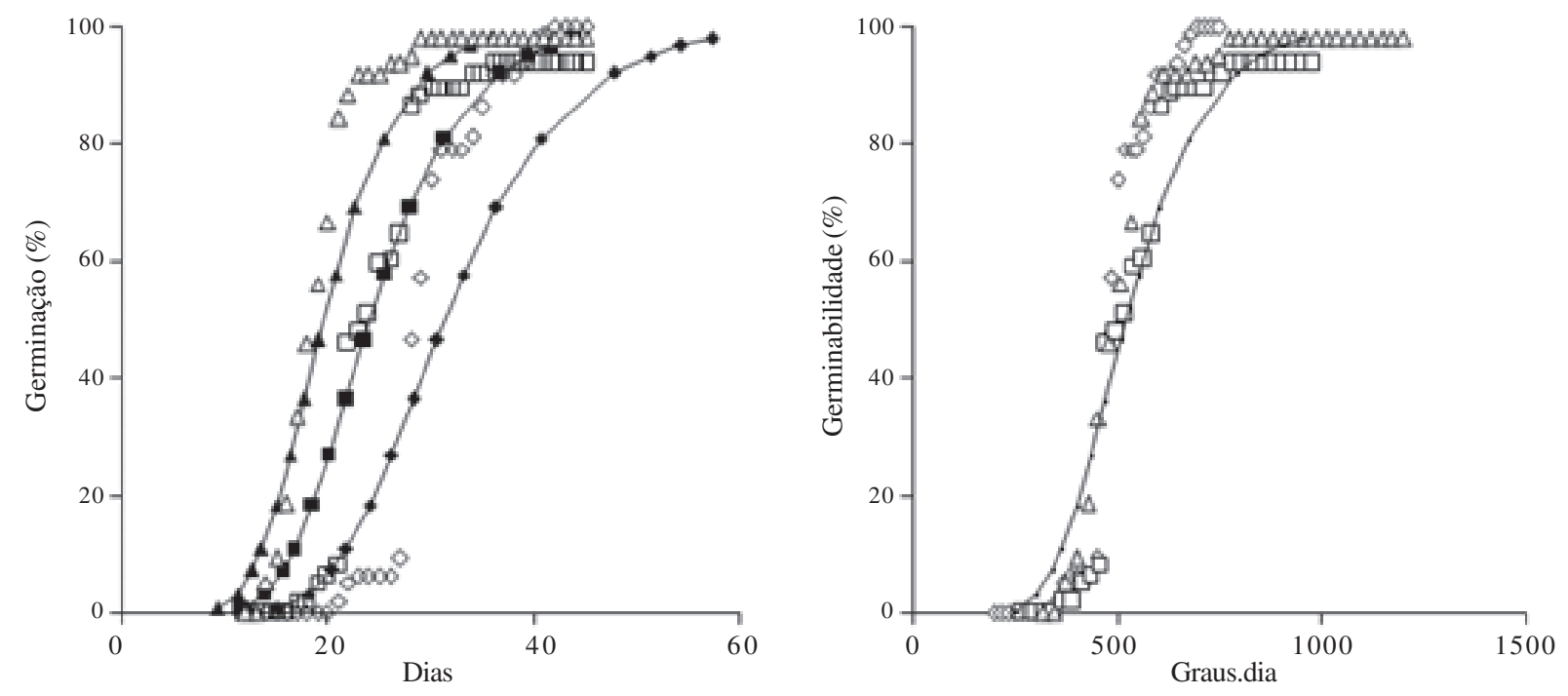

C
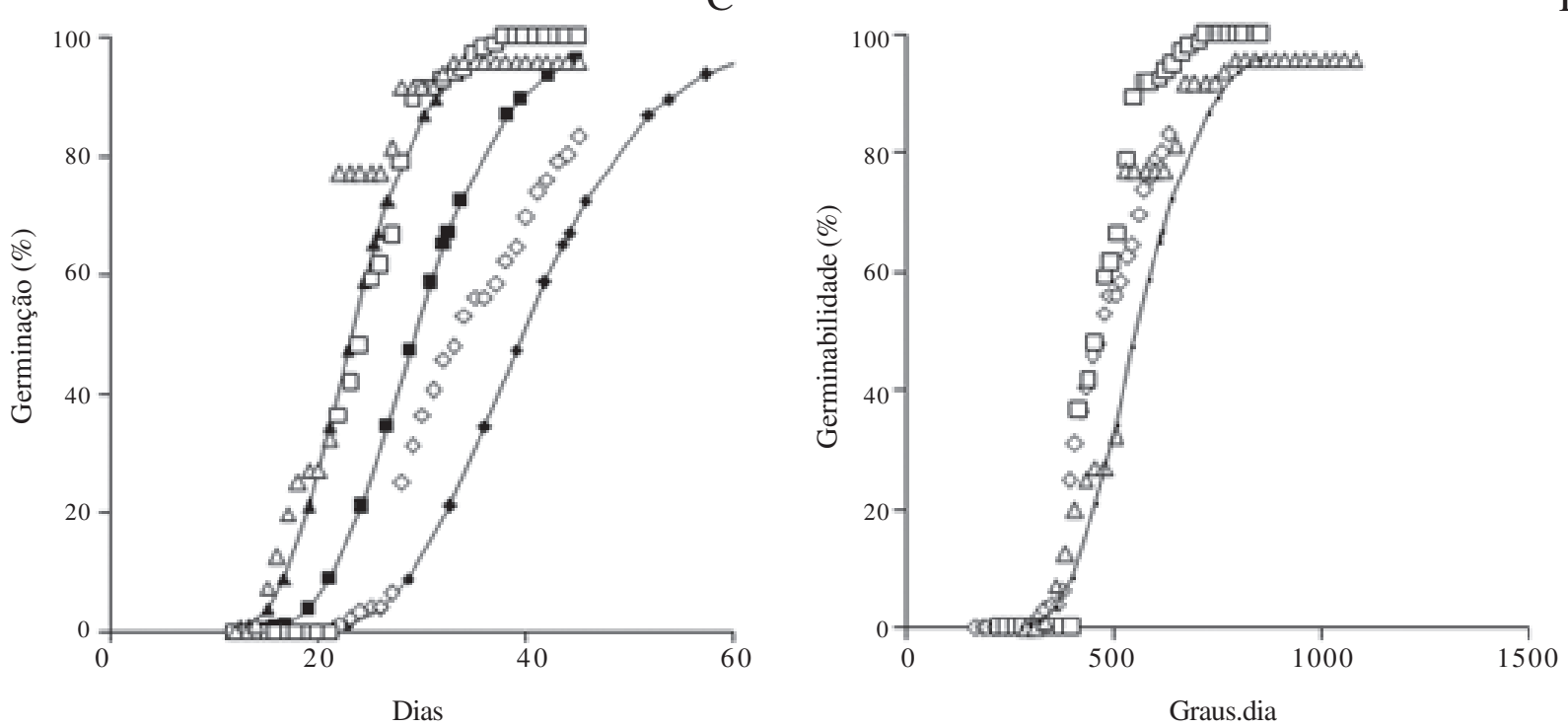

$\mathrm{D}$

Figura 4. Curvas de germinação isotérmica de sementes de sementes de Terstroemia brasiliensis Cambess. A $15^{\circ} \mathrm{C}(\diamond), 20^{\circ} \mathrm{C}(\square)$ e $25^{\circ} \mathrm{C}(\Delta)$, sob luz branca (A e B) e em escuro constante, em escala de dias (A e C) e graus-dia (B e D). Linhas indicam as curvas de germinação a $15^{\circ} \mathrm{C}(\bullet)$, $20{ }^{\circ} \mathrm{C}(\boldsymbol{\bullet})$ e $25{ }^{\circ} \mathrm{C}(\boldsymbol{\Delta})$ na escala de dias (Fig. A, C) e na escala de graus-dia (B e D) previstas pelo modelo $\mathrm{G}=5+(1 / \sigma) .\left(\theta_{\mathrm{g}}-\mu\right)$, onde $\mathrm{G}=$ germinação $(\%)$ e $\theta_{\mathrm{g}}$ é a quantidade de graus-dia necessária para a germinação da fração $g$, com parâmetros $\sigma=0,12841$ e $\mu=2,71637(\mathrm{~A}$ e B); e $\sigma=0,10390$ e $\mu=2,74389$ (C e D). 
desenterrados em junho e julho é possível observar que o ambiente classificado como "clareira úmida" foi desfavorável à germinação in situ. Grosso modo, considerando-se todo o período de coleta, o número de plântulas exumadas foi maior nos ambientes classificados como "secos" do que nos "úmidos" (Fig. 5A). As sementes de T. brasiliensis não germinadas presentes nos envelopes desenterrados foram submetidas a teste
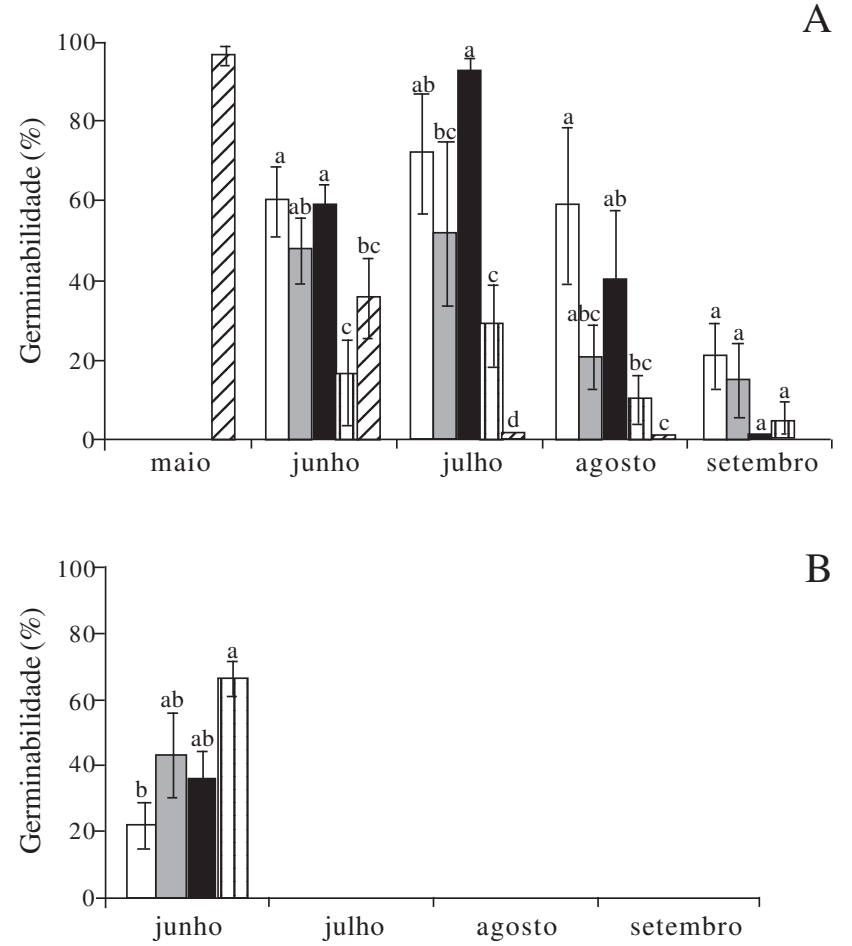

B

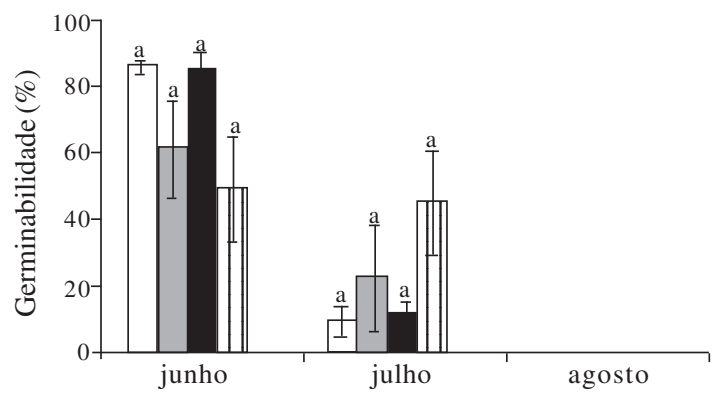

Figura 5. A. Germinabilidade (G) in situ de sementes de Ternstroemia brasiliensis Cambess. coletadas em maio e enterradas no solo $(5 \mathrm{~cm}$ de profundidade) nos ambientes: sub-bosque seco (SS); sub-bosque úmido (SU); clareira seca (CS); e clareira úmida (CU), em uma floresta de Restinga na Ilha do Cardoso, SP, Brasil. B. Germinabilidade em laboratório, a $25^{\circ} \mathrm{C}$ sob luz branca, de sementes exumadas dos ensaios de enterramento. C. Germinação mensal in situ de sementes colocadas sobre a superfície do solo nos ambientes SS, SU, CS e CU. Controle = G de sementes armazenadas em laboratório e submetidas a testes mensais. Letras comparam os tratamentos pelo teste de Tukey $(\alpha=0,05)$ e barras representam os respectivos erros da média. ( $\square=\mathrm{SS}$;

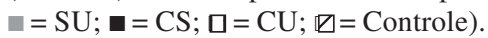

de germinação em laboratório. As porcentagens apresentadas na Fig. 5B, a exemplo dos resultados na Fig. 5A, tomam por base o número inicial de sementes nos envelopes exumados. Observou-se que apenas no primeiro mês as sementes recuperadas apresentaram viabilidade, indicando que a maioria das sementes não germinadas durante o período de enterramento estava viva. A partir do segundo mês nenhuma das sementes exumadas germinou (Fig. 5B).

Sementes de Terstroemia brasiliensis colocadas diretamente sobre a superfície do solo apresentaram germinação acima de $80 \%$ nos ambientes classificados como "secos", sendo os percentuais numericamente inferiores em ambientes "úmidos" (Fig. 5C). Pode-se observar também que a germinação concentrou-se nos dois primeiros da semeadura, cessando a partir do terceiro mês. Levando-se em conta a distribuição das porcentagens de germinação nos meses de junho e julho, ambientes com solos mais bem drenados tendem a propiciar germinação mais rápida, embora a germinação final (somando-se as de junho e julho) tenha sido estatisticamente igual comparando-se os quatro ambientes.

\section{Discussão}

Sementes de Terstroemia brasiliensis armazenadas a $25{ }^{\circ} \mathrm{C}$ apresentaram longevidade relativamente baixa, já que a germinabilidade caiu praticamente a zero após 60 dias, ocorrendo nesse período uma redução de $60 \%$ no teor de umidade das sementes. Em sementes recémcoletadas, o teor de água (37\%) é relativamente alto comparado com o de outras espécies não pioneiras, como Ficus guaranitica $(14,9 \%$, base massa seca), Pachystroma longifollium (20\%) e Hymenaea courbaril $(12,5 \%)$ (Souza \& Válio 2001). Esse comportamento parece incluir T. brasiliensis no grupo das sementes recalcitrantes, que não toleram desidratação e que apresentam baixa longevidade quando armazenadas a seco (Castro et al. 2004). Tais sementes, devido ao seu metabolismo contínuo, perdem a viabilidade se a umidade diminuir abaixo de um valor crítico (Baskin \& Baskin 1998).

Considerando-se que a embebição das sementes de Terstroemia brasiliensis é relativamente rápida, o que indica que os tegumentos não restringem a difusão de água ao embrião, e considerando-se os elevados índices de germinação é possível concluir que sementes de T. brasiliensis não apresentam dormência primária, seja de natureza física (barreira imposta pelo tegumento) seja fisiológica. Desse modo a germinação deve ocorrer logo após a dispersão, não havendo a formação de um banco de sementes persistente ( $>1$ ano) no solo. Essa conclusão 
é reforçada pelos ensaios realizados na Restinga, que mostraram a baixa longevidade de sementes de T. brasiliensis enterradas em diferentes ambientes. Em amostras de solo coletadas na área de estudo nos meses de dezembro/2003 e julho/2004 também não foi detectada a presença de sementes viáveis de T. brasiliensis (Pires, inédito), confirmando que sementes dessa espécie não chegam a formar banco de sementes.

Sementes de Terstroemia brasiliensis não apresentam fotoblastismo, já que não houve diferença na germinabilidade e na velocidade de germinação sob luz e escuro. O tratamento com vermelho extremo, por sua vez, causou apenas uma redução na velocidade de germinação dessa espécie. Myracrodruon urundeuva (aroeira) também não apresentou fotoblastismo na faixa ótima de temperatura nem em condições de alternância térmica (Silva et al. 2002), e uma baixa resposta ao comprimento de onda vermelho extremo foi descrita para sementes de Melicytus ramiflorus (Herron et al. 2000), sendo ambas as espécies consideradas secundárias tardias.

Esses atributos (baixa longevidade no solo, afotoblastismo e não dormência) de Terstroemia brasiliensis são característicos de sementes de espécies tropicais não-pioneiras que em geral não apresentam dormência física (Cardoso 2004), não formam banco de sementes (Denslow 1980) e possuem maior proporção de espécies com sementes insensíveis à luz em comparação com o grupo das pioneiras (Souza \& Válio 2001). Tais caracteres permitem a germinação no subbosque de sementes depositadas sobre a superfície ou mesmo de sementes enterradas, tal como observado em Ocotea pulchella Mart. e Erythroxylum amplifolium em floresta de Restinga (Pires, inédito). A presença do arilo parece não influenciar a capacidade de germinação das sementes de T. brasiliensis, as quais são removidas por aves (Carrasco, comunicação pessoal) que devem atuar principalmente como agentes dispersores, não influenciando o comportamento germinativo das sementes.

Em condições de laboratório, sementes de Terstroemia brasiliensis revelaram-se bastante sensíveis ao alagamento do substrato. Esses resultados sugerem que a saturação hídrica do solo no ambiente de Restinga pode afetar a germinação dessa espécie, a exemplo de Buddleja cordata, árvore pioneira que ocorre em campos de altitude recobertos por vegetação de pequeno porte $\mathrm{e}$ cuja germinação apresenta baixa dependência da luz, mas é limitada principalmente pela umidade do solo (VasquezYanes \& Orozco-Segovia 1990). Observações de campo também sugerem que o excesso de água no solo pode exercer um efeito negativo sobre a capacidade e velocidade de germinação de sementes de T. brasiliensis. Em observações realizadas no mesmo local dos experimentos descritos neste trabalho, em ambiente de sub-bosque, Pires (inédito) encontrou uma maior densidade de regenerantes (plântulas até $30 \mathrm{~cm}$ alt.) dessa espécie em ambientes com solos mais "secos" do que em solos sujeitos a encharcamento. À época da montagem dos ensaios no campo (maio), quando se inicia o período de dispersão das sementes, o lençol freático ainda encontrava-se aflorado em alguns dos ambientes classificados como "clareiras úmidas". Esse enxarcamento do solo não deve ter comprometido muito a germinabilidade das sementes de T. brasiliensis colocadas sobre a superfície, tendo ocorrido germinação no segundo mês do experimento, quando ocorreu redução do nível de água no solo. Nas sementes enterradas, por outro lado, a elevada saturação hídrica aparentemente pode acelerar a deterioração da semente e/ou da plântula. A capacidade de sementes submersas germinarem após uma diminuição do nível da água do solo foi observada em outras espécies arbóreas de florestas higrófilas, tais como Parkia pendula (Scarano \& Crawford 1992) e Calophylum brasiliense (Marques \& Joly 2000). Este mecanismo pode ser muito importante para a ocupação dos microhabitats espaço-temporalmente heterogêneos da Restinga (Scarano et al. 1997). Algumas características fisiológicas das sementes de T. brasiliensis, particularmente as rápidas taxas de embebição e a sensibilidade ao alagamento, podem contribuir para que a germinação e emergência dessa espécie na Restinga ocorram predominantemente durante o período de precipitação e temperatura menos intensas.

As temperaturas constantes de $25^{\circ} \mathrm{C}$ e $30{ }^{\circ} \mathrm{C}$, nas quais tanto a germinabilidade como a velocidade de germinação atingiram os valores mais elevados, podem ser consideradas ótimas para a germinação de Terstroemia brasiliensis. Silva et al. (1997), trabalhando com sementes da espécie não pioneira Esenbeckia leiocarpa, observaram que as temperaturas constantes de $25^{\circ} \mathrm{C}$ e $30{ }^{\circ} \mathrm{C}$ foram as mais favoráveis à germinação, mas somente sob luz vermelha e vermelho extremo. Em T. brasiliensis, a faixa térmica ótima de velocidade da germinação inclui-se dentro da faixa ótima de germinabilidade, ao contrário, por exemplo, de Myracrodruon urundeuva, onde há uma disjunção entre os ótimos de velocidade e germinabilidade (Silva et al. 2002). Com relação à germinabilidade não foi observada interação entre luz e temperatura, ou seja, nas condições experimentais descritas a luz branca não influenciou de maneira significativa a ação da temperatura sobre a porcentagem final de germinação de sementes de T. brasiliensis. Por outro lado, levando-se em conta a sincronização e a velocidade de germinação, variáveis que descrevem a distribuição das porcentagens de germinação ao longo do tempo, provavelmente as condições de luminosidade no ambiente devem influenciar 
a resposta de sementes de $T$. brasiliensis à temperatura. Entre as espécies consideradas pioneiras algumas exibem comportamento fotoblástico em algumas temperaturas e em outras não, como é o caso de Jacaranda mimosifolia (Socolowski \& Takaki 2004). Infelizmente, dado o número relativamente reduzido de temperaturas que puderam ser testadas neste trabalho, não foi possível uma melhor delimitação experimental das temperaturas mínima e máxima da germinação dessa espécie. Com base nos experimentos realizados, entretanto, pode-se estimar que as sementes de T. brasiliensis são potencialmente capazes de germinar em temperaturas relativamente baixas, visto que os valores teóricos estimados de temperatura base foram baixos $\left(-1,5^{\circ} \mathrm{C}\right.$ e $+1{ }^{\circ} \mathrm{C}$, respectivamente sob luz branca e escuro). Tais estimativas evidentemente subestimam a temperatura mínima experimental mas permitem inferir que esta espécie deve germinar em temperaturas mais baixas do que o fazem, por exemplo, sementes da espécie coexistente Ocotea pulchella cujos valores de temperatura base são mais altos (Pires et al., inédito) e cujo pico de emergência de plântulas no ambiente natural ocorre quando as temperaturas estão mais elevadas, diferentemente de $T$. brasiliensis. Como a germinação de T. brasiliensis variou relativamente pouco na faixa de 15 a $35^{\circ} \mathrm{C}$ é possível que o fator temperatura por si só não deva constituir um fator limitante considerável da germinação dessa espécie no ambiente natural, considerando-se as amplitudes de variação térmica anuais registradas nos diferentes ambientes da Restinga. A capacidade de germinar e se desenvolver numa ampla faixa de temperaturas pode contribuir para a amplitude de distribuição de T. brasiliensis, que também ocorre em florestas de altitude (Oliveira Filho et al. 2004; Souza \& Lorenzi 2005), onde a temperatura pode atingir valores baixos. Além disso, o gênero Terstroemia é citado por Oliveira Filho et al. (2004) como característico de florestas nebulares neotropicais.

Levando-se em conta o fato das sementes de Terstroemia brasiliensis não apresentarem dormência, tentou-se neste trabalho a análise das curvas de germinação isotérmica à luz de modelo baseado no conceito de graus-dia (Garcia-Huidobro et al. 1982). Em linhas gerais, o modelo relaciona a ocorrência de um dado processo biológico com a energia térmica (representada pelo produto da quantidade de graus centígrados pelo tempo de exposição) recebida pelo sistema. Conhecendo-se essa relação, representada no caso do processo de germinação pelo parâmetro $\theta_{\mathrm{g}}$, e conhecendo-se $T_{b}$ é possível prever-se teoricamente o tempo necessário para uma dada porcentagem de germinação num regime térmico qualquer. A quantidade de "graus-dia" que um sistema vivo recebe no ambiente natural é representada pela somatória dos produtos da quantidade de ${ }^{\circ} \mathrm{C}$ acima da $\mathrm{T}_{\mathrm{b}}$ multiplicada pelo tempo de exposição (no caso dia). Por exemplo, se $\mathrm{T}_{\mathrm{b}}$ é igual a $10{ }^{\circ} \mathrm{C}$ e a temperatura média no dia foi $11^{\circ} \mathrm{C}$, então 1 grau.dia é acumulado. No caso de T. brasiliensis, um elemento favorável à aplicação do modelo é a tendência de linearidade na relação entre velocidade de germinação e temperatura na faixa infra-ótima. Em regime térmico constante o modelo tende a descrever melhor a germinação de $T$. brasiliensis sob luz branca do que em escuro. Por outro lado, o modelo assume que $\mathrm{T}_{\mathrm{b}}$ seja relativamente constante, independentemente da fração percentual considerada, condição que permite que as curvas de germinação em diferentes temperaturas caiam numa única curva quando plotadas em escala de graus-dia (Larsen \& Bibby 2005). Entretanto, no caso de T. brasiliensis é possível que $\mathrm{T}_{\mathrm{b}}$ seja dependente da fração germinante, especialmente quando as sementes germinam em escuro, levando-se em conta os desvios dos pontos em relação à curva esperada. De qualquer modo, essa é uma hipótese que precisa ser novamente testada utilizando-se um espectro de temperaturas mais amplo.

$O$ presente trabalho sugere que os atributos fisiológicos das sementes e parâmetros da germinação de Terstroemia brasiliensis podem ser considerados para explicar sua distribuição no ambiente natural, semelhante ao de outras árvores não-pioneiras. Provavelmente o nível de água no solo, especialmente a condição de alagamento, em florestas de Restinga deva ser o principal fator limitante para a germinação desta espécie, que provavelmente deve germinar sem problemas nas condições de luz e temperatura normalmente encontradas no ambiente da Restinga.

\section{Agradecimentos}

Os autores agradecem ao CNPq, pela bolsa de doutorado concedida a primeira autora e pelo auxilio financeiro (proc. 473005/2003-4); e ao Projeto "Diversidade, Dinâmica e Conservação em Florestas do Estado de São Paulo: 40 ha de Parcelas Permanentes" (Biota/Fapesp), pelo apoio.

\section{Referências}

Amaral-Barolli, A. \& Takaki, T. 2001. Phytochrome controls achene germination in Bidens pilosa L. (Asteraceae) by very low fluence response. Brazilian Archives of Biology and Technology 44: $121-124$.

Baskin, C.C. \& Baskin, J.M. 1998. Seeds: Ecology, Biogeography and Evolution of Dormancy and Germination. São Diego, Academic Press.

Bradford, K. 1995. Water relations in seed germination. In: J. Kigel \& G. Galili (eds.). Seed Development and Germination. New York, Marcel Dekker Inc. 
Cardoso, V.J.M. 2004. Dormência: estabelecimento do processo. In: A.G. Ferreira \& F.E. Borghetti (orgs.). Germinação: do Básico ao Aplicado. Porto Alegre, Artmed.

Castro, R.D.; Bradford, K. \& Hilhorst, H.W.M. 2004. Desenvolvimento de sementes e conteúdo de água. In: A.G. Ferreira \& F.E. Borghetti (orgs.). Germinação: do Básico ao Aplicado. Porto Alegre, Artmed.

Denslow, J.S. 1980. Gap partitioning among tropical rainforest trees. Biotropica 12: 47-55.

Garcia-Huidobro, J.; Monteith, J.L. \& Squire, G.R. 1982. Time, temperature and germination of pearl millet (Pennisetum typhoides) I. Constant temperature. Journal of Experimental Botany 33: 288-296.

Gummerson, R.J. 1986. The effect of constant temperatures and osmotic potentials on the germination of sugar beet. Journal of Experimental Botany 37: 729-741.

Herron, H.; Clemens, J. \& Greer, D.H. 2000. Contrasting seed germination responses to red and far-red light in Leptospermum scoparium and Melicytus ramiflorus. Australian Journal of Plant Physiology 27: 1069-1076.

Joly, C.A. 1991. Flooding tolerance in tropical trees. In: M.B. Jackson, D.D. Davis \& H. Lambersa (eds.). Plant Life Under Oxygen Deprivation: Ecology, Physiology and Biochemistry. The Hague, SPB Academic.

Labouriau, L.G. 1983. A Germinação das Sementes. Washington D.C, Secretaria Geral da Organização dos Estados Americanos.

Labouriau, L.G \& Agudo, M. 1987. On the physiology of seed germination in Salvia hispanica L. I. Temperature effects. Anais da Academia Brasileira de Ciências 59: 37-56.

Larsen, S.U. \& Bibby, B.M. 2005. Differences in thermal time requirement for germination of $\mathrm{t}$ hree turfgrass species. Crop Science 45: 2030-2037.

Lobo, P.C. \& Joly, C.A. 1996. Ecofisiologia da germinação de sementes de Talauma ovata St. Hil. (Magnoliaceae), uma espécie típica de matas de brejo. Revista Brasileira de Botânica 19: 35-40.

Marques, M.C.M. \& Joly, C.A. 2000. Aspectos da germinação e do crescimento de Calophyllum brasiliense (Clusiaceae), uma espécie típica de locais inundados. Acta Botanica Brasilica 14: 113-120.

Mayer, A.M. \& Poljakoff-Mayber, A. 1989. The Germination of Seeds. Oxford, Pergamon Press.

Oliveira Filho, A.T.; Carvalho, D.A.; Fontes, M.A.L.; Van Den Berg, E.; Curi, N. \& Carvalho, W.A.C. 2004. Variações estruturais do compartimento arbóreo de uma floresta semidecídua altomontana na chapada das Perdizes, Carrancas, MG. Revista Brasileira Botânica 27: 291-309.

Pinheiro, F. \& Borghetti, F. 2003. Light and temperature requeriments for germination of seeds of Aechmea nudicaulis (L.) Griesebachand and Streptocalyx floribundus (Martius ex Schultes F.) Mez (Bromeliaceae). Acta Botanica Brasilica 17: 27-35.

Raich J.W. \& Khoon G.W. 1990. Effect of canopy openings on tree seed germination in a Malayan dipterocarp forest. Journal of Tropical Ecology 6: 203-217.
Salimon, C.I. \& Negrelle, R.B. 2001. Natural regeneration in a quarternary coastal plain in the southern Brazilian Atlantic Rain Forest. Brazilian Archives of Biology and Technology 44: 155-163.

Scarano, F.R. \& Crawford, R.M.M. 1992. Ontogeny and the concept of anoxia-tolerance: the case of the Amazonian leguminous tree Parkia pendula. Journal of Tropical Ecology 8: 349-352.

Scarano, F.R.; Ribeiro, K.T.; Moraes, L.F.D. \& Lima, H.C. 1997. Plant establishment on flooded and unflooded patches of a freschwater swamp forest in southeastern Brazil. Journal of Tropical Ecology 14: 793-803.

Silva, E.M.N. 1988. Determinação de umidade. In: F.C.M. PiñaRodrigues. Manual de Análise de Sementes Florestais. Campinas, Fundação Cargill.

Silva, S.M. \& Britez, R.M. 2005. A vegetação da planície costeira. In: M.C.M. Marques \& R.M. Britez (orgs.). História Natural e Conservação da Ilha do Mel. Curitiba, Editora UFPR.

Silva, A.; Castellani, E.D.; Aguiar, I.B.; Sader, R. \& Rodrigues, T.J.D. 1997. Interação de luz e temperatura na germinação de sementes de Esenbeckia leiocarpa (guarantã). Revista do Instituto Florestal 9: 57-64.

Silva, L.M.M.; Rodrigues, T.J.D. \& Aguiar, I.B. 2002. Efeito da luz e da temperatura na germinação de sementes de Aroeira (Myracrodruon urundeuva Allemão). Revista Arvore 26: 691-697.

Socolowski F. \& Takaki, M. 2004. Germination of Jacaranda mimosifolia G. Don (Bignoniaceae) seeds: effects of light, temperature and water stress. Brazilian Archives of Biology and Technology 47: 785-792.

Sokal, R.R. \& Rohlf, F.J. 1969. Biometry. W.H. São Francisco, Freeman and Co.

Souza, R.P. \& Valio, I.F.M. 2001. Seed size, seed germination and seedling survival of brazilian tropical trees species differing in succecional status. Biotropica 33: 447-457.

Souza, V.C. \& Lorenzi, H. 2005. Botânica Sistemática: Guia Ilustrado para Identificação das Famílias de Angiospermas da Flora Brasileira, Baseado em APG II. Nova Odessa, Instituto Plantarum.

Sugyama, M. 1998. Estudo de florestas da restinga da Ilha do Cardoso, Cananéia, São Paulo, Brasil. Boletim do Instituto de Botânica 11: $119-159$.

Swaine, M.D. \& Whitmore, T.C. 1988. On the definition of ecological species groups in tropical rain. Plant Ecology 75: 81-86.

Vázquez-Yanes, C.R. \& Orozco-Segovia, A. 1990. Ecological significance of light controlled seed germination in two contrasting tropical habitats. Oecologia 83: 171-175.

Whitmore, T.C. 1978. Gaps in the forest canopy. In: P.B. Tomlinson \& M.H. Zimmerman (eds.). Tropical Trees as Living Systems. New York, Cambridge University Press.

Whitmore, T.C. 1989. Canopy gaps and the two major groups of forest trees. Ecology 70: 536-538.

Versão eletrônica do artigo em www.scielo.br/abb e http://www.botanica.org.br/acta/ojs 